Article

\title{
Designed Conducting Polymer Composites That Facilitate Long-Lived, Light-Driven Oxygen and Hydrogen Evolution from Water in a Photoelectrochemical Concentration Cell (PECC)
}

\author{
Mohammed Alsultan 1,2,3, Khalid Zainulabdeen ${ }^{1,2}$, Pawel Wagner 1,2 ${ }^{\mathbb{D} \text {, }}$ \\ Gerhard F. Swiegers $1,2, * \mathbb{D}$ and Holly Warren ${ }^{1,2}$ (D) \\ 1 Intelligent Polymer Research Institute, University of Wollongong, Wollongong, NSW 2522, Australia; \\ mfka287@uowmail.edu.au (M.A.); kwyz764@uowmail.edu.au (K.Z.); pawel@uow.edu.au (P.W.); \\ hwarren@uow.edu.au (H.W.) \\ 2 ARC Centre of Excellence for Electromaterials Science, University of Wollongong, \\ Wollongong, NSW 2522, Australia \\ 3 Department of Basic Education, University of Mosul, Mosul 41002, Iraq \\ * Correspondence: swiegers@uow.edu.au; Tel.: +61-2-4221-5577
}

Received: 1 November 2019; Accepted: 11 December 2019; Published: 14 December 2019

\begin{abstract}
Light-driven water-splitting to generate hydrogen and oxygen from water is typically carried out in an electrochemical cell with an external voltage greater than $1.23 \mathrm{~V}$ applied between the electrodes. In this work, we examined the use of a concentration/chemical bias as a means of facilitating water-splitting under light illumination without the need for such an externally applied voltage. Such a concentration bias was created by employing a $\mathrm{pH}$ differential in the liquid electrolytes within the $\mathrm{O}_{2}$-generating anode half-cell and the $\mathrm{H}_{2}$-generating cathode half-cell. A novel, stretchable, highly ion-conductive polyacrylamide $\mathrm{CsCl}$ hydrogel was developed to connect the two half-cells. The key feature of the cell was the half-cell electrodes, which comprised thin-film conducting polymer composites that were previously designed to maximize light-driven catalysis at moderate $\mathrm{pH}$. Upon being connected with the hydrogel in the presence of light irradiation ( 0.25 sun intensity on each electrode), the half-cells spontaneously produced hydrogen and oxygen from water, without the need for an externally applied voltage bias greater than $1.23 \mathrm{~V}$. The cell operated reliably and efficiently for $14 \mathrm{~h}$ of continuous testing. These results demonstrate the fundamental feasibility of light-driven water-splitting in a photoelectrochemical concentration cell when employing electrodes that operate efficiently at moderate $\mathrm{pH}$, even with low levels of light illumination. The designed conducting polymer composites proved ideal in that regard.
\end{abstract}

Keywords: water-splitting; electrolysis; concentration cell; photoelectrochemical cell; ion bridge; hydrogel; cesium chloride

\section{Introduction}

The generation of hydrogen $\left(\mathrm{H}_{2}\right)$ and oxygen $\left(\mathrm{O}_{2}\right)$ from water $\left(\mathrm{H}_{2} \mathrm{O}\right)$ requires a minimum of $1.23 \mathrm{~V}$ of electrical energy $\left(E^{\circ}\right)$ and $0.25 \mathrm{~V}$ of heat energy (which is also supplied in the form of electricity), giving a total minimum theoretical energy requirement of $1.48 \mathrm{~V}$ [1]. This quantity is known as the thermoneutral voltage $\left(E_{T N}\right)$ [1]. In practice, even the most efficient commercial electrolyzers have to operate at significantly higher voltages (typically $>1.9 \mathrm{~V}$ ) because large overpotentials, beyond these theoretical minima, must also be applied to drive the reaction [1]. Direct hydrogen and oxygen production from water $\left(\mathrm{H}_{2} \mathrm{O}\right)$ using illumination by sunlight is a key aim for future renewable and 
sustainable clean energy. Major efforts were made to develop electrodes (namely, anodes for $\mathrm{O}_{2}$ generation and cathodes for $\mathrm{H}_{2}$ generation) that are capable of facilitating such direct, light-driven water-splitting when combined in a single photoelectrochemical cell (PEC) [2]. However, except for a few impractically elaborate and expensive multi-junction semiconductor cells (known popularly as "artificial leaves") [3], all water-splitting PECs developed to date require the application of additional energy, beyond that already present in the irradiating sunlight. This additional energy is typically supplied in the form of an external electrical voltage that is applied between the $\mathrm{O}_{2}$-generating anode and the $\mathrm{H}_{2}$-generating cathode of the cell, which exceeds $1.23 \mathrm{~V}$. Because of the energy input provided by the irradiating sunlight, the additional energy may be smaller than the net energy present in the $\mathrm{H}_{2}$ and $\mathrm{O}_{2}$ produced (which is equivalent to $1.48 \mathrm{~V}$ ). The overall process is then still energy-positive and "green". The main disadvantage is the need for an external electrical connection that is capable of providing $>1.23 \mathrm{~V}$, which has practical and cost implications.

There are alternative means to supply the additional energy needed. One such means is to chemically, instead of electrically, assist the light-driven reaction. This can be achieved by separating the PEC into two half-cells (namely, an anode half-cell and a cathode half-cell) and employing a different $\mathrm{pH}$ in each half-cell [4]. The $\mathrm{H}^{+}$and $\mathrm{OH}^{-}$concentrations at the anode and cathode are then dissimilar. The resulting concentration differential may create some of the needed additional voltage. Cells of this type are also known as "concentration cells". They, effectively, constitute a small battery that provides additional energy needed to assist the light-driven process.

While concentration cells of this type were examined before [5-9], they proved challenging to implement because present-day (photo)catalysts require extreme $\mathrm{pH}$ to operate effectively. $\mathrm{O}_{2}$-generating anode catalysts typically require a $\mathrm{pH}$ greater than $\sim 13$, while $\mathrm{H}_{2}$-generating cathode catalysts need a $\mathrm{pH}$ of less than $\sim 0.5$. That is, a large $\mathrm{pH}$ differential of $>12.5 \mathrm{pH}$ units, is generally needed. However, it is difficult to maintain so large a $\mathrm{pH}$ differential, especially when the two half-cells are connected by an ion bridge. Moreover, when the $\mathrm{pH}$ at the anode falls below the above threshold, or the $\mathrm{pH}$ at the cathode rises above it, then operation ceases as the respective catalysts become ineffective. Cells of this type, therefore, to be very short-lived, if active at all.

The key to fabricating longer-lived PEC concentration cells of this type is to develop anode/cathode photocatalysts that operate effectively at less extreme $\mathrm{pHs}$, even with low levels of light illumination.

In recent work, we developed conducting polymer composites that, when applied to electrode surfaces as thin films, synergistically amplified photocatalytic $\mathrm{O}_{2}{ }^{-}$and $\mathrm{H}_{2}{ }^{-}$generation from water at moderate $\mathrm{pH}$ even under light of low $(0.25$ sun $)$ intensity $[10,11]$. The thin films comprised the conducting polymer poly(3,4-ethylenedioxidethiophene) (PEDOT) embedded with nanoparticulate $\mathrm{Ni}$ ("nano-Ni") (as catalyst) and reduced graphene oxide ( $\mathrm{rGO}$ ) (as conductor) in very specific molar ratios. The best coating for the anode electrode was $0.62 \mu \mathrm{m}$ thick and utilized a molar ratio of 4.5 (C; PEDOT):1 (Ni):9.5 (C; rGO/carbons not in PEDOT) [10]. It was previously found to be an order of magnitude more catalytically active for $\mathrm{O}_{2}{ }^{-}$generation than the industry-standard catalyst, platinum $(\mathrm{Pt})$, in $0.2 \mathrm{M}$ $\mathrm{Na}_{2} \mathrm{SO}_{4}$ adjusted to $\mathrm{pH} 12$ [10]. The best coating for the cathode electrode was $0.61 \mu \mathrm{m}$ thick and had a molar ratio of 5.6 (C; PEDOT):1 (Ni):5.2 (C; rGO/other) [11]. It was more catalytically active than Pt in $\mathrm{H}_{2}$ generation in $0.1 \mathrm{M} \mathrm{H}_{2} \mathrm{SO}_{4}$ (pH1) [11]. The specific molar ratios in these films were needed to create a synergistic matching of their conductivity, connectivity, and catalytic capability. That is, at the above molar ratios, the conducting polymer electrically connected the largest number of catalytic sites (thereby maximizing the catalytically active area) by the shortest, most conductive pathway (thereby maximizing the catalytic activity of each site).

Given these electrodes, we wanted to see whether they could be deployed to create a long-lived PEC concentration cell. To this end, we also developed a novel, highly efficient ion bridge comprising a stretchable polyacrylamide-CsCl (PAAm-CsCl) hydrogel. Unlike similar separators [12], the hydrogel optimally combined durable mechanical and electrical properties.

We report here such a water-splitting photoelectrochemical concentration cell (PECC) employing the above conducting polymer composite catalysts (at the above $\mathrm{pH}$ conditions) at the anode and 
cathode, with the above ion bridge connecting the two half-cells. When illuminated with light ( 0.25 sun), the cell spontaneously split water into $\mathrm{O}_{2}$ (at the anode) and $\mathrm{H}_{2}$ (at the cathode) without need for an external voltage of $>1.23 \mathrm{~V}$. The cell operated steadily and continuously for $>14 \mathrm{~h}$ of testing.

\section{Results}

\subsection{The Photoelectrochemical Concentration Cell (PECC) of This Work}

Figure 1 schematically depicts the photoelectrochemical concentration cell (PECC) developed in this work. A photograph of the cell is provided in Figure S1 (Supplementary Materials).

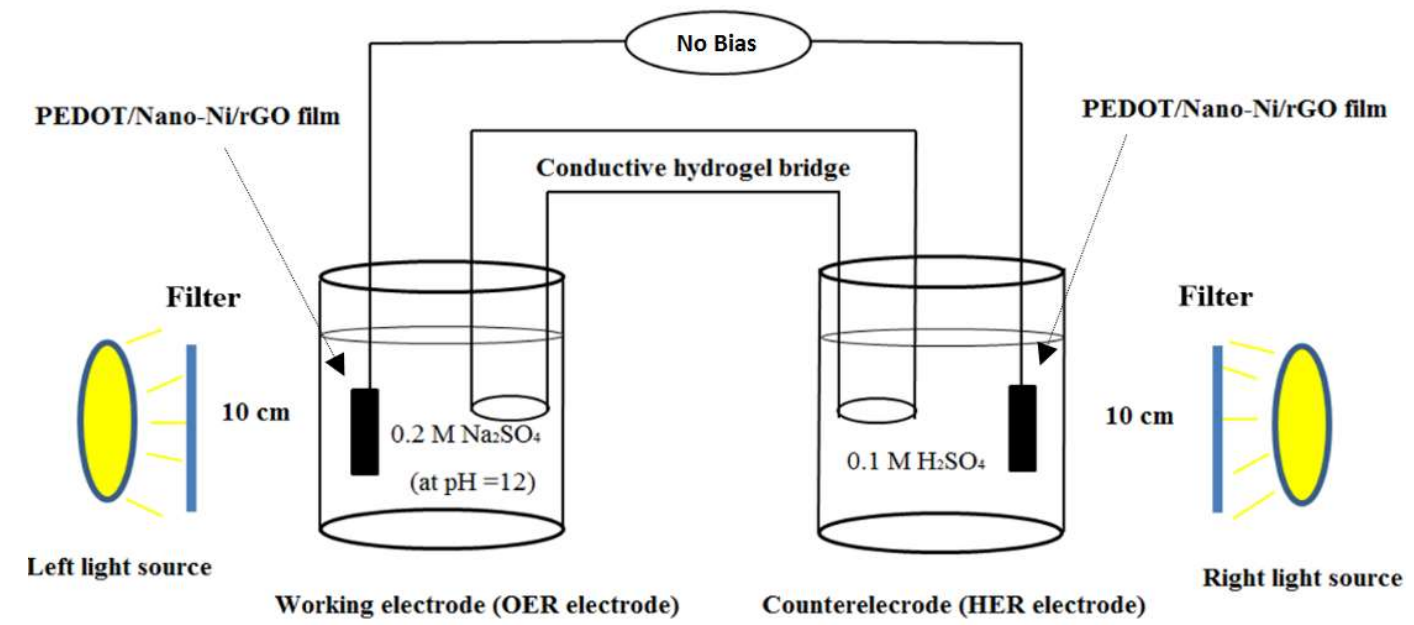

Figure 1. Schematic illustration of the photoelectrochemical concentration (PEC) cell studied in this work, utilizing poly(3,4-ethylenedioxidethiophene) (PEDOT)/nano-Ni/reduced graphene oxide (rGO) films for water-splitting with no external voltage applied. A light-driven anode for catalysis of the oxygen evolution reaction (OER) (in the left-hand half-cell) is combined with a light-driven cathode for catalysis of the hydrogen evolution reaction (HER) (in the right-hand half-cell). A hydrogel bridge is provided between the two half-cells. A photograph of the PEC cell set-up is provided in Figure S1 (Supplementary Materials).

As can be seen in Figure 1, the PECC comprised two half-cells: (1) an $\mathrm{O}_{2}$-producing anode half-cell (labeled as the "working electrode" or the "OER (oxygen evolution reaction) electrode") and (ii) an $\mathrm{H}_{2}$-producing cathode half-cell (labeled as the "counter electrode" or the "HER (hydrogen evolution reaction) electrode"). The electrodes in each of these half-cells consisted of conductive fluorine tin oxide (FTO) glass slides coated with thin films of PEDOT embedded with nano-Ni and rGO in the molar ratios noted in Section 1 (labeled as "PEDOT/nano-Ni/rGO film" in Figure 1).

Two SoLux daylight MR16 halogen light bulbs ( $12 \mathrm{~V}, 50 \mathrm{~W}, 24^{\circ} ; 0.25$ sun intensity) were employed to illuminate the surfaces of the electrodes in each half-cell ("left light source" and "right light source" in Figure 1). The incident light was, in each case, filtered through a Thorlabs visible-light bandpass filter $(315-710 \mathrm{~nm})$ that was placed $1.5 \mathrm{~cm}$ in front of the light source. The bandpass filter removed any heat (infrared wavelength) generated by the light source.

To connect the two half-cells in Figure 1, we needed an ion-permeable interface to close the electrical circuit comprising the two half-cells. In previous studies, ion-exchange membranes, such as Nafion, were employed as the ion-permeable interface between two half-cells of this type. However, in this work, we sought to develop a hydrogel separator with a longer path length for ion diffusion. Provided that such a separator can maintain a high level of ionic conductivity with robust performance, it should exhibit some advantages over an ion-exchange membrane. These include [5] (i) improved operation over a narrower and more moderate range of $\mathrm{pH}$, with (ii) an accompanying, improved capacity for long-term stability in water-splitting, at (iii) lower cost. 
The most successful of the separators examined was a novel, mechanically robust, stretchable polyacrylamide- $\mathrm{CsCl}$ (PAAm-CsCl) hydrogel that was fabricated as described in Section 4. The hydrogel was fixed in a U-tube that was then used to connect the anode and cathode half-cells, as depicted in Figure 1. The hydrogel was highly ion-conductive.

In the resulting PECC depicted in Figure 1, a concentration-induced voltage $\left(\Delta E_{(\mathrm{V})}\right)$ facilitated water-splitting when the electrodes were illuminated with light. The voltage was created by the different $\mathrm{pH}$ of the liquid electrolytes within the two half-cells; it can be calculated, at room temperature, using Equation (1) [4,5].

$$
\Delta E_{(\mathrm{V})}=0.059 \times \Delta \mathrm{pH},
$$

where $\Delta E_{(\mathrm{V})}$ is the concentration-induced voltage, and $\Delta \mathrm{pH}$ is the difference in $\mathrm{pH}$ between the two half-cells.

\subsection{Testing of the PECC}

The PECC, thus fabricated, was subjected to a series of tests in order to assess its performance. The first involved linear swept voltammetry (LSV) in the range 1.1-1.5 V (cell voltage), with and without light illumination. As can be seen in Figure 2, at a cell voltage of $1.5 \mathrm{~V}$ with both electrodes illuminated by light ( 0.25 sun intensity), the current density increased from $368 \mu \mathrm{A} / \mathrm{cm}^{2}$ without illumination to $415 \mu \mathrm{A} / \mathrm{cm}^{2}$ with illumination.

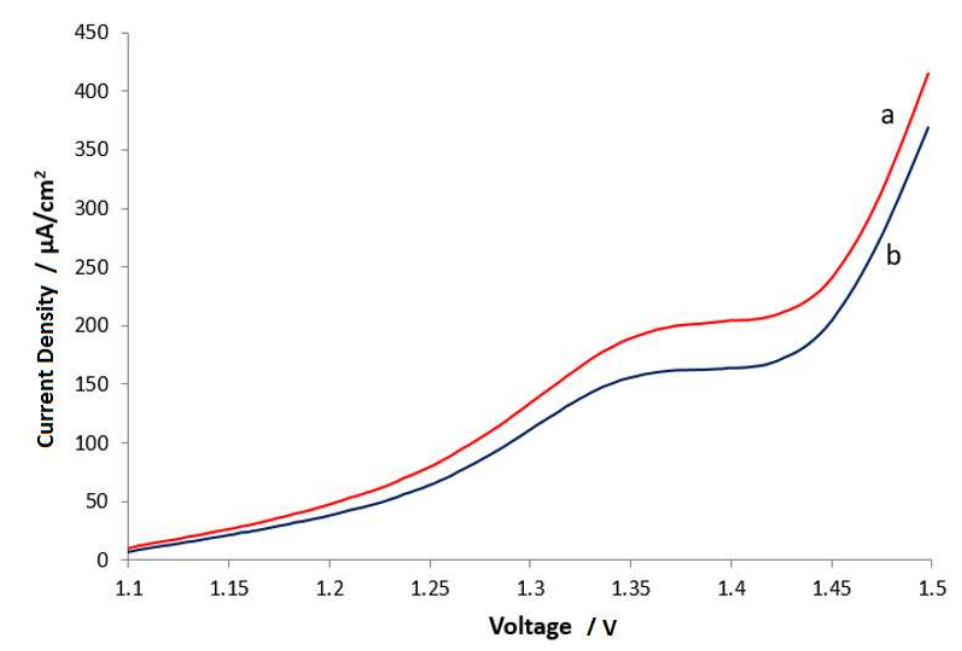

Figure 2. Linear sweep voltammogram (LSV) of the cell in Figure 1 with (a) and without (b) illumination of both electrodes with light of 0.25 sun intensity. Scan rate: $5 \mathrm{mv} / \mathrm{s}$.

Chronoamperometry was also carried out at cell voltages of $1.23 \mathrm{~V}$ and $1.5 \mathrm{~V}$. The former corresponds to the theoretical minimum electrical energy $\left(E^{\circ}\right)$ needed to facilitate catalytic water-splitting. The latter is just above the thermoneutral voltage $(1.48 \mathrm{~V})$, which corresponds to the voltage at which water electrolysis is said to be $100 \%$ energy-efficient [1-5].

As can be seen in Figure 3a, when 1.23 V was applied, the "dark" current (without light illumination) was $140-142 \mu \mathrm{A} / \mathrm{cm}^{2}$. When the lights were switched on, the current increased to $154-156 \mu \mathrm{A} / \mathrm{cm}^{2}$. Thus, the photocurrent arising from the light illumination (IP(i) in Figure 3a) was $14 \mu \mathrm{A} / \mathrm{cm}^{2}$.

When a bias of $1.5 \mathrm{~V}$ was applied, the dark current was $366-373 \mu \mathrm{A} / \mathrm{cm}^{2}$, while, with light, it was increased to $386-391 \mu \mathrm{A} / \mathrm{cm}^{2}$, producing $18-20 \mu \mathrm{A} / \mathrm{cm}^{2}$ photocurrent (IP(ii) in Figure 3b). 

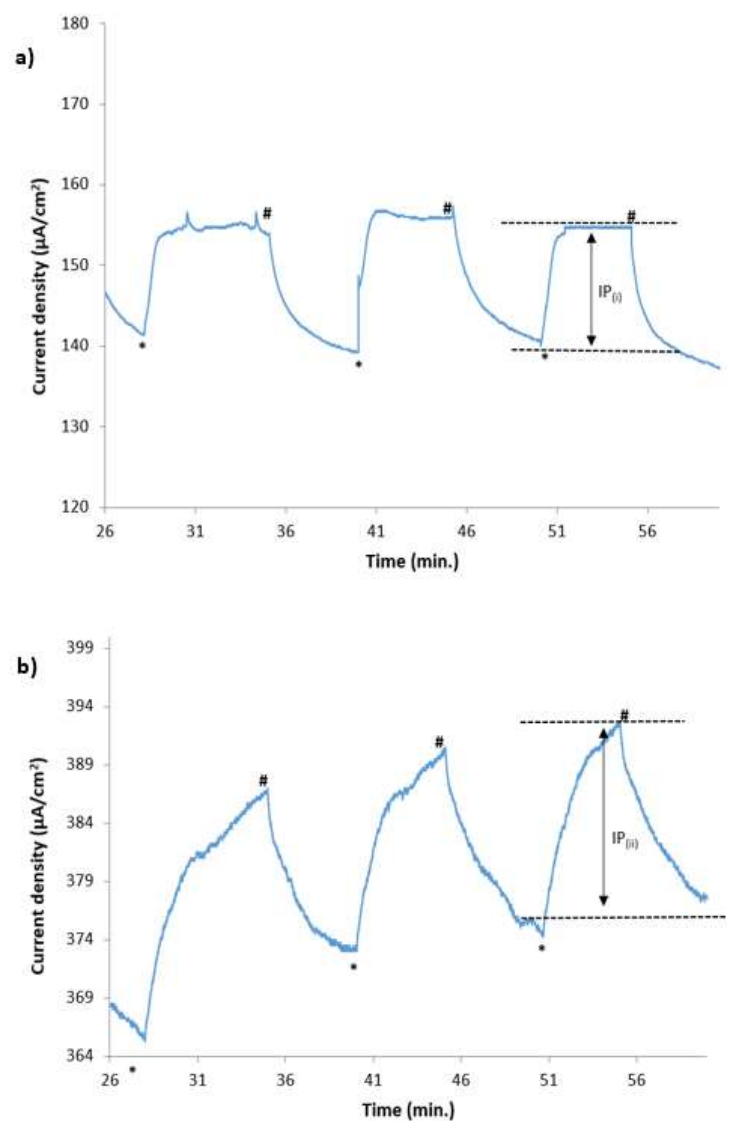

Figure 3. Chronoamperograms of catalytic water-splitting with and without light illumination of each electrode (0.25 sun), as illustrated in Figure 1 at cell voltages of (a) $1.23 \mathrm{~V}$ and (b) $1.5 \mathrm{~V}$ for $1 \mathrm{~h}$ of operation (* signifies that the light illumination was turned on; \# signifies that the light illumination was turned off).

In theory, it is, of course, not possible to perform water-splitting at $1.23 \mathrm{~V}$ since this corresponds to the minimum electrical energy, but not total energy, needed to split water at room temperature. However, the energy from the light illumination, along with the chemical energy provided by the differing $\mathrm{pH}$ conditions at the cathode and anode, allowed the cell to readily split water at $1.23 \mathrm{~V}$.

To assess how long-lived this effect was, we ran chronoamperometry at $1.23 \mathrm{~V}$ and $1.5 \mathrm{~V}$ for $14 \mathrm{~h}$.

As can be seen in Figure 4, when the lights were turned on, the currents increased steadily at both cell voltages. They stabilized after $3 \mathrm{~h}$ of operation, at $192 \mu \mathrm{A} / \mathrm{cm}^{2}$ at $1.23 \mathrm{~V}$ and $484 \mu \mathrm{A} / \mathrm{cm}^{2}$ at $1.5 \mathrm{~V}$. Thereafter, the current at $1.5 \mathrm{~V}$ started declining very gradually to $59 \%$ of its stabilized current after $14 \mathrm{~h}$ of operation. By contrast, the current density at $1.23 \mathrm{~V}$ was more stable over $14 \mathrm{~h}$ of operation, declining to $88.2 \%$ of its stabilized current.

At around the 11th hour of testing, the lights were switched off for a short period and then switched on again. As can be seen in Figure 4, the currents at $1.23 \mathrm{~V}$ and $1.5 \mathrm{~V}$ fell to their "dark" currents during this period of time but quickly recovered when the lights were turned on again. The values IP (i) and IP (ii) in Figure 4 indicate the currents that were created by the light illumination at $1.23 \mathrm{~V}$ and $1.5 \mathrm{~V}$, respectively. As can be seen, light illumination provides a major source of energy for the water-splitting. 


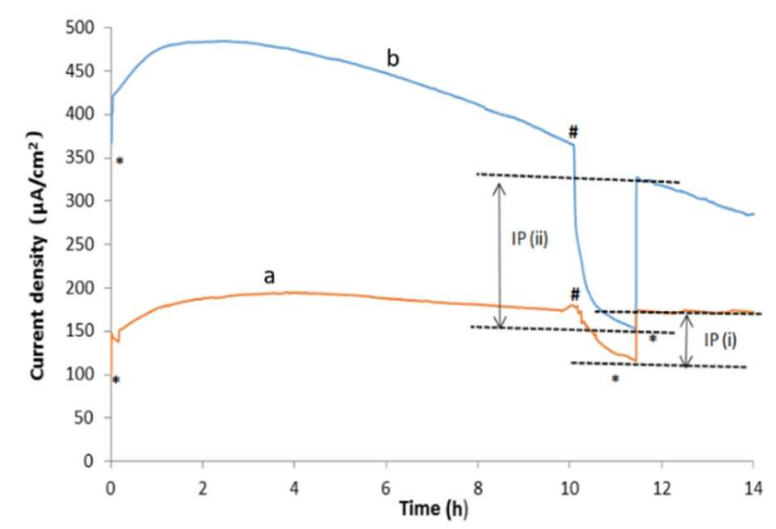

Figure 4. Chronoamperogram of catalytic water-splitting with and without light illumination (0.25 sun at each electrode), of fluorine tin oxide (FTO) glass slide electrodes coated with a PEDOT/nano-Ni-nano/rGO thin-film as illustrated in Figure 1 at a two-electrode cell voltage of (a) $1.23 \mathrm{~V}$ and (b) $1.5 \mathrm{~V}$ for $14 \mathrm{~h}$ of operation ( ${ }^{*}=$ "light on", \# = "light off").

\subsection{Physical and Electrical Properties of the Conductive Polyacrylamide $\mathrm{CsCl}$ Hydrogel Separator}

Key to the catalytic performance described above was the hydrogel separator. For this reason, we now discuss the physical and electrical characteristics of the separator.

The hydrogel separator was developed to display high conductivity of up to $310 \pm 31 \mathrm{mS} / \mathrm{cm}$ (Figure 5). This conductivity is significantly larger than previously reported for polyacrylamide hydrogels, which was $0.22 \mathrm{mS} / \mathrm{cm}$ [12]. The high conductivity was undoubtedly due to the $\mathrm{Cs}^{+}$and $\mathrm{Cl}^{-}$ions in the gel. $\mathrm{Cs}^{+}$ions have a greater mobility through the polymer matrix due to the shielding effect of an additional two electron shells when compared with $\mathrm{Li}^{+}$ions, which would interact more with the polymer chains.

Moreover, the water content (\%) in the hydrogel increased from $65 \%$ to $95 \%$ when it was immersed in both electrolytes, providing better transport of water molecules, thereby enhancing the hydrogel conductivity, as shown in Table 1 . The $\mathrm{pH}$ of the hydrogel increased only slightly over $14 \mathrm{~h}$ of PEC operation (Table 1). The conductivity also improved during operation, from $265 \pm 21 \mathrm{mS} / \mathrm{cm}$ to $310 \pm$ $31 \mathrm{mS} / \mathrm{cm}$.

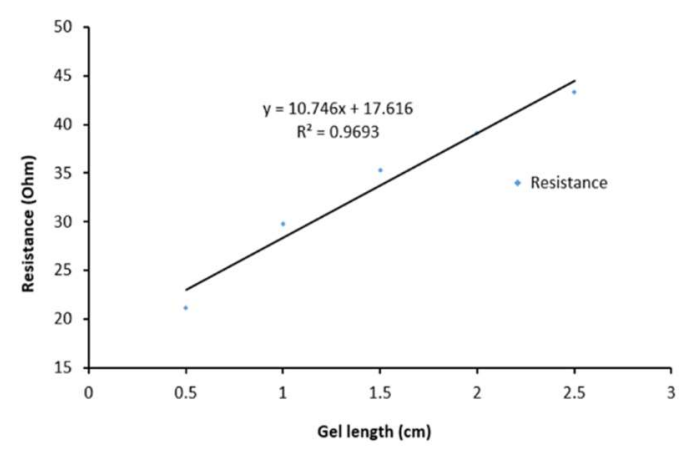

Figure 5. Resistance as a function of length of the hydrogel separator used in this study (prior to operation in the cell). The geometric area of each electrode was $4 \mathrm{~cm}^{2}$.

Table 1. Conductivity, $\mathrm{pH}$, and water content of hydrogel polyacrylamide-CsCl bridge (PAAm-CsCl).

\begin{tabular}{ccc}
\hline Parameter & Initial & After $\mathbf{1 4} \mathbf{~ h}$ \\
\hline Conductivity $(\mathrm{mS} / \mathrm{cm})$ & $265 \pm 21$ & $310 \pm 31$ \\
Water content $(\%)$ & 65 & 95 \\
$\mathrm{pH}$ & 2.5 & 3.1 \\
\hline
\end{tabular}


The mechanical properties of the hydrogel were also examined to assess its mechanical durability [13-16]. Figure 6 shows tensile and compression test analyses (before use). The hydrogel displayed a tensile strength of $26 \pm 7 \mathrm{kPa}$, with an ability to stretch to approximately three times its original length $(298 \% \pm 19 \%$; Table 2$)$. This provided a conductive ion-bridge for reliable operation even under circumstances of significant dimensional change. Its tensile modulus was $18 \pm 3 \mathrm{kPa}$ (Table 2).

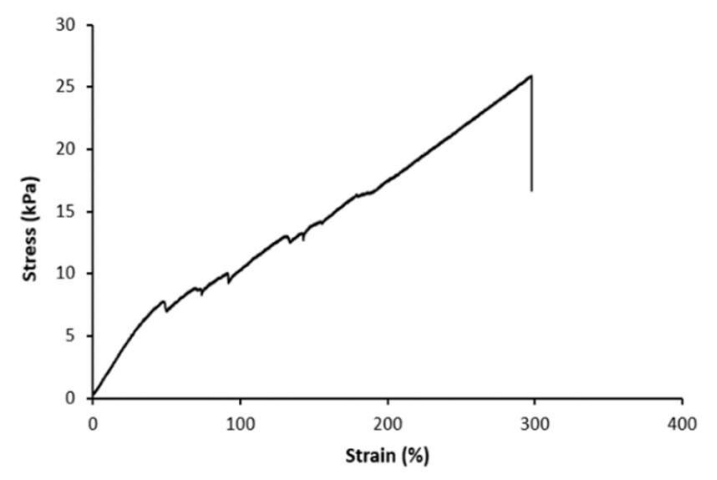

Figure 6. Stress-strain curve for the polyacrylamide- $\mathrm{CsCl}$ (PAAm-CsCl hydrogel) of this study.

Table 2. Tensile test parameters for PAAm-CsCl hydrogel.

\begin{tabular}{cc}
\hline Parameter & Values \\
\hline Tensile modulus & $18 \pm 3 \mathrm{kPa}$ \\
Tensile strength & $26 \pm 7 \mathrm{kPa}$ \\
Extension to failure & $198 \% \pm 19 \%$ \\
\hline
\end{tabular}

Compression test analysis was also carried out on the hydrogel to assess its mechanical characteristics under compression. Figure 7 depicts the resulting graph; Table 3 summarizes key data. As can be seen, the data for compression modulus, ultimate compression, and strain to failure (\%) revealed the hydrogel to have robust mechanical properties.

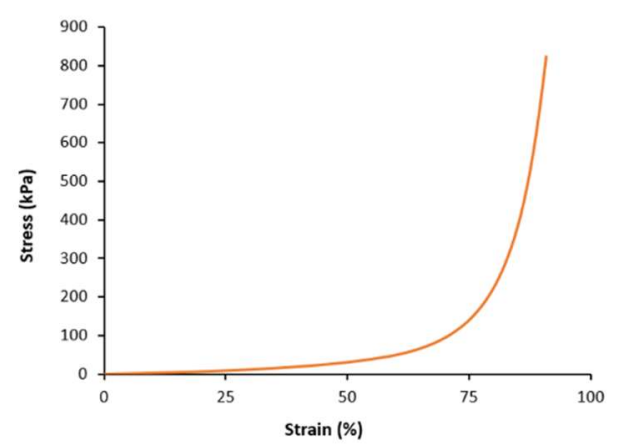

Figure 7. Compression test analysis of PAAm-CsCl hydrogel.

Table 3. Compression test parameters for PAAm- $\mathrm{CsCl}$ hydrogel.

\begin{tabular}{cc}
\hline Parameter & Values \\
\hline Compression modulus & $24 \pm 2 \mathrm{kPa}$ \\
Ultimate compression & $824 \pm 31 \mathrm{kPa}$ \\
Strain to failure & $91 \% \pm 8 \%$ \\
\hline
\end{tabular}

These robust properties demonstrate that the separator is capable of undergoing even large dimensional changes of the type that may occur during cell operation without significantly changing 
its conductivity. The novelty of the PAAm-CsCl hydrogel lies in it possessing durable mechanical and electrical properties. It is not trivial to prepare a hydrogel having both of these properties simultaneously optimized.

Finally, the hydrogel sample was stored at room temperature $\left(21^{\circ} \mathrm{C}\right)$ and $50 \%$ relative humidity $(\mathrm{RH})$ to test its water retention capacity over 15 days. Samples exhibited gradual shrinkage as shown in Figure 8. After 15 days, the water loss of the hydrogel was $11 \%$ and no longer changed. The main reason for the slow water loss during this period is the fact that $\mathrm{CsCl}$ salt is a hygroscopic agent. It absorbs moisture from the air to balance the water content and substitute the water loss in the hydrogel. For this reason, the hydrogel remained rich in water, enhancing its mechanical and electrical durability when compared to other gels $[13,15,17]$.

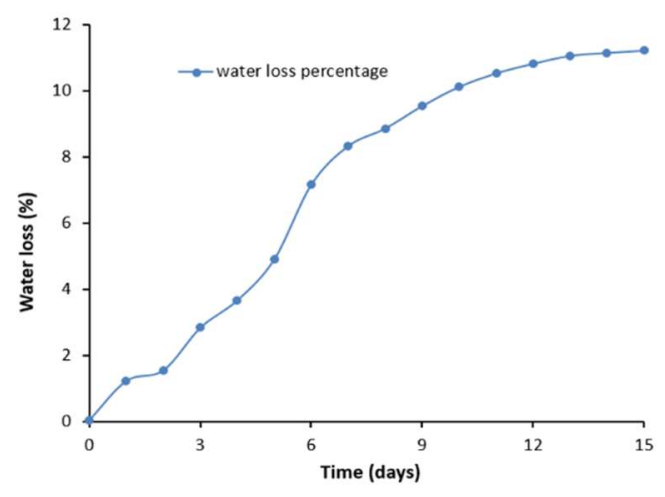

Figure 8. A typical plot of water loss percentage and time in days for the PAAm-CsCl hydrogel.

\section{Discussion and Conclusions}

Two highly active thin-film electrodes comprising the conducting polymer, poly(3,4-ethylenedioxidethiophene) (PEDOT) embedded with nanoparticulate $\mathrm{Ni}$ ("nano-Ni") (as catalyst) and reduced graphene oxide (rGO) (as conductor) in very specific molar ratios, were studied as the working and counter electrodes in a chemically assisted, water-splitting PEC. The $\mathrm{O}_{2}$-generating anode was immersed in aqueous $0.2 \mathrm{M} \mathrm{Na}_{2} \mathrm{SO}_{4}$ adjusted to a $\mathrm{pH}$ of 12 . The $\mathrm{H}_{2}$-generating cathode was immersed in an electrolyte of $0.1 \mathrm{M} \mathrm{H}_{2} \mathrm{SO}_{4}$. The half-cell electrolytes were connected via a novel, conductive hydrogel bridge that exhibited excellent charge transfer mobility between the two half-cell electrolytes. Illumination of each electrode with light of 0.25 sun intensity resulted in generation of $\mathrm{O}_{2}$ (at the anode) and $\mathrm{H}_{2}$ (at the cathode) without any need to apply an external voltage beyond $1.23 \mathrm{~V}$. This light-driven, chemically assisted water-splitting continued for at least $14 \mathrm{~h}$ of testing at $1.23 \mathrm{~V}$ and $1.5 \mathrm{~V}$. The current at $1.23 \mathrm{~V}$ was sustained and relatively constant over $14 \mathrm{~h}$ of PEC operation, declining only $11.8 \%$ from its stabilized current. The current at $1.5 \mathrm{~V}$ showed a steeper decline to $59 \%$ of its stabilized value after $14 \mathrm{~h}$ of operation.

This study demonstrated the fundamental feasibility of longer-lived, light-driven water-splitting photoelectrochemical concentration cells (PECCs). Such cells require specialized photocatalysts capable of operating at more moderate, nearer-neutral $\mathrm{pH}$, such as the designed conducting polymer thin films that were used. A careful choice of salt bridge is also essential. Ionic polyacrylamide hydrogels offer an attractive option in this respect.

\section{Materials and Methods}

\subsection{Synthesis of Poly(3,4-ethylenedioxidethiophene) (PEDOT)/Nano-Ni/Reduced Graphene Oxide (rGO) and Electrochemical Testing}

Fluorine-doped tin oxide (FTO) slides were supplied by Zhuhai Kaivo Electronic Components Co. (Zhuhai, China). Ni nanoparticles $(99.9 \%, 20 \mathrm{~nm}$ ) were provided by Skyspring Nanomaterials (Houston, TX, USA). GO and rGO was prepared as described previously $[10,11]$. The PEDOT/nano-Ni/rGO 
films on FTO glass slides were fabricated as described previously $[10,11]$. Electrochemical procedures followed those employed previously [10,11].

\subsection{Preparation of Polyacrylamide Hydrogel}

Acrylamide monomer (99.9\%), $N, N^{\prime}$-methylenebis(acrylamide), cesium chloride ( $\left.\geq 99.9 \%\right)$, and $\alpha$-ketoglutaric acid were purchased from Sigma Aldrich (St. Louis, MO, USA). Polyacrylamide hydrogel-forming solution was synthesized by adding, at room temperature $\left(2{ }^{\circ} \mathrm{C}\right), 20 \%(w / v)$ $\mathrm{CsCl}$ to Milli-Q water (20 g of $\mathrm{CsCl}$ salt dissolved in $100 \mathrm{~mL}$ of MilliQ water). Acrylamide monomer powder was added to yield a $4 \%(w / v)$ acrylamide concentration. Then, $470 \mu \mathrm{L}$ of $2 \% w / v$ $\mathrm{N}, \mathrm{N}$-methylenbis(acrylamide) and $0.014 \%(w / v) \alpha$-ketoglutaric acid were added as the cross-linking co-polymer and photoinitiator, respectively. The gel solution was stirred and degassed in a vacuum desiccator for $20 \mathrm{~min}$ under 0.1 bar pressure, at room temperature. The acrylamide solution was poured into a $U$-shaped glass tube (diameter $=20 \mathrm{~mm}$, length $130 \mathrm{~mm}$ ). Solutions were cross-linked using a Dymax BlueWave 75 Rev 2.0 ultraviolet (UV) Light (Dymax Corporation, Torrington, CT, USA) at $1.15 \mathrm{~W} / \mathrm{cm}^{2}$ intensity.

\subsection{Polyacrylamide Hydrogel Characterization}

For mechanical tensile testing, solutions were poured into a $15 \mathrm{~cm} \times 15 \mathrm{~cm}$ box, cured, and cut into "dog-bone" shapes (conforming to JIS-K625060). Compression testing was carried out on gels which were cast and cured in a cylindrical mold (diameter $=18 \mathrm{~mm}$, height $=10 \mathrm{~mm}$ ). For electrical characterization, hydrogel samples (height $=6 \mathrm{~mm}$, width $=5 \mathrm{~mm}$ ) of length between $5 \mathrm{~mm}$ and 25 $\mathrm{mm}$ were cast in plastic molds with reticulated vitreous carbon foam (RVC, ERG Aerospace, Oakland, CA, USA, 20 pores per inch) at each end.

The initial water content of the polyacrylamide (PAAm) hydrogel was determined by weighing it and subtracting the mass of the original components. The subsequent loss percentage was evaluated using Equation (2). Masses were recorded using a digital lab balance.

$$
\text { Water loss } \%=\frac{\text { Mass of hydrogel }- \text { Starting mass of hydrogel }}{\text { Starting mass of hydrogel }} \times 100 \text {. }
$$

The hydrogel electrical conductivity was characterized by recording the electrical impedance for frequencies between $1 \mathrm{~Hz}$ and $100 \mathrm{kHz}$ using a custom-designed set-up, as described in previous studies $[18,19]$.

Supplementary Materials: The following are available online at http://www.mdpi.com/2504-477X/3/4/108/s1: Figure S1: Photograph of the PECC in Figure 1.

Author Contributions: Conceptualization, G.F.S.; methodology, M.A. and K.Z.; investigation, M.A. and K.Z.; writing —original draft preparation, G.F.S.; writing—review and editing, G.F.S; supervision, P.W., G.F.S. and H.W.

Funding: This research was funded, in part, by (1) the Australian Research Council (ARC) Center of Excellence Scheme (Grant CE140100012), (2) the Australian National Fabrication Facility (ANFF) Materials Node, (3) the Australian Research Council (ARC) Linkage, Infrastructure, Equipment, and Facilities (LIEF) Scheme (Grant LE160100063 located at the University of Wollongong), and (3) the Government of Iraq (PhD scholarship for M.A.).

Acknowledgments: Portions of this work are drawn from the PhD thesis of Mohammed Alsultan. The authors acknowledge Adam Taylor for design and printing of the custom-built apparatus. The authors acknowledge the use of facilities and the assistance of Tony Romeo.

Conflicts of Interest: The authors declare no conflicts of interest. 


\section{References}

1. Jensen, J.O.; Bandur, V.; Bjerrun, N.J.; Jensen, S.H.; Ebbesen, S.; Mogensen, M.; Trophoj, N.; Yde, L. Pre-Investigation of Water Electrolysis; Publication PSO-F\&U 2006-1-6287; RISO and the Danish Technical University: Roskilde, Denmark, 2008; references therein.

2. Bak, T.; Nowotny, J.; Rekas, M.; Sorrell, C.C. Photo-electrochemical hydrogen generation from water using solar energy materials-related aspects. Int. J. Hydrog. Energy 2002, 27, 991-1022. [CrossRef]

3. Nocera, D.G. The artificial leaf. Acc. Chem. Res. 2012, 45, 767-776. [CrossRef] [PubMed]

4. Selli, E.; Chiarello, G.L.; Quartarone, E.; Mustarelli, P.; Rossetti, I.; Forni, L. A photocatalytic water splitting device for separate hydrogen and oxygen evolution. Chem. Commun. 2007, 5022-5024. [CrossRef] [PubMed]

5. Kaplan, A.; Korin, E.; Halevy, S.; Bettelheim, A. Chemical bias of electrochemical and photoelectrochemical water splitting using a hydrogel separator. Electrochem. Commun. 2015, 60, 97-99. [CrossRef]

6. Antoniadou, M.; Bouras, P.; Strataki, N.; Lianos, P. Hydrogen and electricity generation by photoelectrochemical decomposition of ethanol over nanocrystalline titania. Int. J. Hydrog. Energy 2008, 33, 5045-5051. [CrossRef]

7. Hernandez-Pagan, E.A.; Vargas-Barbosa, N.M.; Wang, T.; Zhao, Y.; Smotkin, E.S.; Mallouk, T.E. Resistance and polarization losses in aqueous buffer-membrane electrolytes for water-splitting photoelectrochemical cells. Energy Environ. Sci. 2012, 5, 7582-7589. [CrossRef]

8. Berger, A.; Segalman, R.A.; Newman, J. Material requirements for membrane separators in a water-splitting photoelectrochemical cell. Energy Environ. Sci. 2014, 7, 1468-1476. [CrossRef]

9. Walczak, K.; Chen, Y.; Karp, C.; Beeman Jeffrey, W.; Shaner, M.; Spurgeon, J.; Sharp Ian, D.; Amashukeli, X.; West, W.; Jin, J.; et al. Modeling, simulation, and fabrication of a fully integrated, acid-stable, scalable solar-driven water-splitting system. ChemSusChem 2015, 8, 544-551. [CrossRef] [PubMed]

10. Alsultan, M.; Balakrishnan, S.; Choi, J.; Jalili, R.; Tiwari, P.; Wagner, P.; Swiegers, G.F. Synergistic amplification of water oxidation catalysis on Pt by a thin-film conducting polymer composite. ACS Appl. Energy Mater. 2018, 1, 4235-4246. [CrossRef]

11. Alsultan, M.; Choi, J.; Jalili, R.; Wagner, P.; Swiegers, G.F. Synergistic amplification of catalytic hydrogen generation by a thin-film conducting polymer composite. Catal. Sci. Technol. 2018, 8, 4169-4179. [CrossRef]

12. Chen, B.; Lu, J.J.; Yang, C.H.; Yang, J.H.; Zhou, J.; Chen, Y.M.; Suo, Z. Highly stretchable and transparent ionogels as nonvolatile conductors for dielectric elastomer transducers. ACS Appl. Mater. Interfaces 2014, 6, 7840-7845. [CrossRef] [PubMed]

13. Bhadani, R.; Mitra Uttam, K. Synthesis and studies on water swelling behaviour of polyacrylamide hydrogels. Macromol. Symp. 2016, 369, 30-34. [CrossRef]

14. Gupta, N.V.; Shivakumar, H.G. Investigation of swelling behavior and mechanical properties of a $\mathrm{pH}$-sensitive superporous hydrogel composite. Iran. J. Pharm. Res. IJPR 2012, 11, 481-493.

15. Ahmed, E.M. Hydrogel: Preparation, characterization, and applications: A review. J. Adv. Res. 2015, 6, 105-121. [CrossRef]

16. Ullah, F.; Othman, M.B.H.; Javed, F.; Ahmad, Z.; Akil, H.M. Classification, processing and application of hydrogels: A review. Mater. Sci. Eng. C 2015, 57, 414-433. [CrossRef]

17. Sun, J.Y.; Keplinger, C.; Whitesides George, M.; Suo, Z. Ionic skin. Adv. Mater. 2014, 26, 7608-7614. [CrossRef]

18. Bai, Y.; Chen, B.; Xiang, F.; Zhou, J.; Wang, H.; Suo, Z. Transparent hydrogel with enhanced water retention capacity by introducing highly hydratable salt. Appl. Phys. Lett. 2014, 105, 151903-151908. [CrossRef]

19. Warren, H.; Gately Reece, D.; O’Brien, P.; Gorkin, R., III; in het Panhuis, M. Electrical conductivity, impedance, and percolation behavior of carbon nanofiber and carbon nanotube containing gellan gum hydrogels. J. Polym.Sci. Part B Polym. Phys. 2014, 52, 864-871. [CrossRef]

(C) 2019 by the authors. Licensee MDPI, Basel, Switzerland. This article is an open access article distributed under the terms and conditions of the Creative Commons Attribution (CC BY) license (http://creativecommons.org/licenses/by/4.0/). 